\title{
Formação de professores: desafios à educação inclusiva
}

\author{
Lázara Cristina da Silva ${ }^{1}$
}

\section{Formação docente: fios, tons e cores}

A formação docente continua sendo um desafio na contemporaneidade, considerando que o tempo e as condiçóes reais para sua concretização esbarram-se na volatilidade das propostas deste tempo presente.

Esse processo é uma colcha tecida a múltiplos fios, com tons e cores diferentes. Cada um expressa seu compromisso e entendimento sobre educaçáo e cidadania. Este texto compromete-se com o direito à educação gratuita, pública, de todos. Para tal, apresenta uma perspectiva de formação alinhada com esse pensamento.

Atualmente, o tempo que se coloca é marcado pela pressa, pela busca da informação, em detrimento do conhecimento. Desta forma, as pessoas buscam um curso cuja agilidade na certificação lhes permita a inserção, o mais rápido possível, no mercado de trabalho. Sendo assim, a formação ofertada e desejada ocorre pautada apenas na primeira fase do processo: o da informação. Não há tempo hábil para se chegar ao conhecimento, pois a realidade atual é marcada por um

1 UFU - Universidade Federal de Uberlândia. Faculdade de Educação - Programa de Pós-Graduação em Educação. Grupo de Estudos e Pesquisa Políticas e Práticas em Educação Especial e Inclusão (Gepepes). Uberlândia - Minas Gerais - Brasil. lazara@ufu.br 
fluxo de informações intenso, no qual tudo está em permanente mudança. Apesar de o conhecimento ser "um recurso flexível, fluido, sempre em expansão e em mudança” (HARGREAVES, 2003, p.33), o mesmo não pode ser considerado como sinônimo de informação.

A informação é a primeira fase do estudo, é a sua matéria-prima. É o ponto de partida para a realização de um trabalho mais aprofundado, que levará ao conhecimento, este sim, elementar para a atuação profissional (CASTELLS, 2002, 2003; COUTINHO; LISBÔA, 2011).

A realidade contemporânea está estruturada na produção e promoção da sociedade da informaçãa, do conhecimento e da aprendizagem. Por conseguinte, é necessário que a formação docente seja pensada para ser exercitada nessa sociedade, compreendendo e interagindo com uma instituição educacional marcada por tais princípios.

O desafio que se coloca para a formação atual envolve justamente a capacidade de trabalhar com os acadêmicos, instrumentalizando-os para agir de forma planejada, refletida, sensível, crítica e compromissada, para no seu desempenho profissional, ser

[...] capaz de desenvolver nos estudantes competências para participar e interagir num mundo global, altamente competitivo, que valoriza o ser-se flexível, criativo, capaz de encontrar soluçôes inovadoras para os problemas de amanhá, ou seja, a capacidade de compreendermos que a aprendizagem não é um processo estático mas algo que deve acontecer ao longo de toda a vida. (COUTINHO; LISBÔA, 2011, p.5)

Não se trata de formar um profissional alheio à realidade, mas situado, coerente e comprometido com os valores sociais, políticos e culturais de seu povo. Náo é um profissional do passado, que encare o conhecimento como um fato pronto e acabado, mas tampouco pode ser um profissional que não tenha conhecimentos que o possibilitem compreender e analisar a realidade de forma a se posicionar criticamente. Inevitavelmente, a formação desse profissional não ocorrerá de forma tão volátil e acelerada como se espera: há que se ter o tempo da reflexão, do amadurecimento e do aprofundamento.

As informações constituem a base do conhecimento, mas a aquisição deste, implica, antes de mais, o desencadear de uma série de operaçóes intelectuais, que colocam em relação os novos dados com as informaçóes armazenadas previamente pelo indivíduo. $\mathrm{O}$ conhecimento adquire-se, pois, quando as diversas informaçōes se inter-relacionam mutuamente, criando uma rede de significaçôes que se interiorizam. Na atualidade, uma das perturbaçóes provocadas pelos médias é o fato de que o homem moderno crê ter acesso à significação dos acontecimentos, simplesmente porque recebeu informaçáo sobre aqueles. (PELLICER, 1997, p.88)

Por conseguinte, a produção de um conhecimento não ocorre de forma instantânea, ela requer tempo para exercitar a capacidade de articular, de refletir, de 
questionar e de generalizar. É nesse processo que o conhecimento será alcançado, na medida em que se atribui um olhar crítico, indagativo, de certo modo duvidoso para a informação, que o acadêmico irá correlacionar esta informação com outras, de fontes diferentes, articulando-as, estabelecendo conexôes etc., assim, será capaz de fazer o exercício da generalização, da relação e aplicação deste na vida cotidiana, ou seja, na realidade para a qual está se qualificando.

Portanto, a formação de professores hoje precisa aliar-se a esta preocupação: trabalhar com a informação para chegar ao conhecimento e repensar os mecanismos de ensino e de aprendizagem.

No entanto, a profissão docente esbarra na dificuldade, pouco vivenciada por outras profissóes, qual seja, a grande proximidade por um tempo considerável que os ingressantes no processo de qualificação possuem com a profissão. Quando estes se inserem nos cursos de formação inicial (graduação/licenciatura), possuem uma trajetória de, no mínimo, quatorze anos de escolarização. Nesse período, incorporam um contingente de práticas, considerados por Pimenta (1996), saberes da experiência, que interferem diretamente na sua prática futura, ou seja, o tempo de formação, muitas vezes, é muito curto para modificar tais estruturas arraigadas pelos anos de convívio cotidiano com a docência.

Logo, a superação de modelos arcaicos é o primeiro passo. A realidade atual requer um docente que, além de ter competência para trabalhar com as tecnologias da informaçáo e da comunicação, seja capaz de interagir, de navegar na internet, de manusear softwares, de trabalhar pedagogicamente de forma crítica e criativa as informaçóes disponíveis nos meios de comunicação e informação que estáo dispostas de forma difusa e desarticulada.

Nesta perspectiva, a formação do professor precisa ser capaz de desenvolver no seu egresso habilidades para que este atue no sentido de agregar elementos que lhe possibilitem, no exercício profissional, atuar na promoção de condiçóes para que seus alunos desenvolvam capacidades cognitivas "necessárias para transcender do pensamento elementar e alcançar o pensamento crítico" (COUTINHO; LISBÔA, 2011, p.10).

Tais habilidades formativas precisam desencadear no docente a preocupação em pensar o seu exercício profissional no sentido de refletir/planejar suas aulas priorizando o trato com as informações disponíveis para transformá-las em conhecimento. Tal exercício formativo precisa ser construído/experimentado de forma a subsidiá-los a realizar escolhas metodológicas que os possibilitem a utilização de experiências significativas e reais para exercitar em suas atividades cotidianas de ensino e aprendizagem:

a) um olhar crítico, duvidoso, inquisitivo (o avaliar de diferentes pontos de vista a informação recebida/contatada);

b) compor, decompor e recompor a informação, verificando os interesses envolvidos na sua produção/divulgaçáo, identificar com quais princípios 
e quem se compromete (o exercício de analisar os fatos, de compreender as procedências, as articulaçóes e as relaçóes de poder envolvidas) e;

c) o propositivo, a generalização e aplicação do conhecimento (o relacionar das informaçóes acessadas com a realidade e dimensionar seus compromissos éticos, políticos, sociais e culturais) (JONASSEN, 2007).

Diante do exposto, a formação docente inicial e/ou continuada precisa, no mínimo, estar compromissada com o desenvolvimento e aprofundamento do conhecimento, focando três pilares: o geral (os fundamentos), o específico (a área de atuação) e o pedagógico. ${ }^{2}$

A fundamentação geral relacionada aos embasamentos básicos é necessária no sentido de que a docência é uma profissão que demanda uma articulação ampliada com o conhecimento. Envolve-se com o trato diário com pessoas, para tanto, há que se compreender sobre cultura, organizaçáo social, filosofia, psicologia do desenvolvimento, política educacional e geral etc.; tais aspectos fundamentarão a compreensão do universo no qual o profissional irá atuar. Será um ingrediente fundamental para desencadear o exercício do avaliar, elementar à prática docente no contexto atual.

A fundamentação específica, relacionada aos saberes científicos próprios da área que irá atuar, consolidará a produção de um conhecimento peculiar de forma mais precisa e aprofundada, que subsidiará sua ação profissional. Tais conhecimentos o auxiliaráo no desencadear o exercício do analisar, do compreender, do articular e dimensionar, pois fundamentarão sua capacidade de compor e decompor o objeto em análise, exercitar a aplicação do referido conhecimento, fazer conjecturas, promover a sua articulação e generalização em diferentes contextos, propor alternativas, enfim, produzir saberes.

A fundamentação pedagógica, por sua vez, irá atuar nos três momentos (avaliar, analisar e compreender, articular e dimensionar) de forma a apresentar e consolidar saberes relacionados ao ensinar e ao aprender.

Com esses conhecimentos, os docentes encontrarão elementos para pensar o movimento do planejamento de suas açóes, a partir da compreensão das diferentes formas de ensinar e de aprender, das variadas formas de organização curricular e dos sistemas de ensino, da história de como essas experiências ocorreram, bem como dos fundamentos legais que respaldam a educação nacional.

2 Historicamente, a formação de professores tem ocorrido em diferentes espaços. No entanto, destaca-se que a formação desejada e defendida neste texto não é possível de ocorrer em ambientes que se comprometem apenas com o ensino, principalmente focados nas demandas da sociedade contemporânea apresentadas anteriormente. Defende-se uma formação pautada no tripé: ensino, pesquisa e extensão, logo, realizada em universidades, náo em institutos de formação, como as açóes governamentais defendem. 
A realidade evidencia que, no processo formativo, a relação com o conhecimento precisa ser alterada, logo, não é possível continuar trabalhando considerando que os conceitos de ensinar e aprender estejam fundamentados na reprodução e na memorização, bem como que estes são demarcados em um espaço/ tempo definidos. Isto, pois, não se ensina uma única vez, nem tampouco o aprender ocorre de forma linear e acabada. Ensinar e aprender são movimentos dinâmicos, constantes e infindáveis, por conseguinte, se está sempre ensinando algo de forma diferente e, aprendendo também, por caminhos diferentes.

Neste contexto, não é concebível pensar em um processo formativo com tempo/espaço definidos. A formação deixou de ter um tempo único para ser um processo contínuo, ininterrupto, em suma, um projeto de vida.

Isto pois a contemporaneidade se encarregou de romper com a dicotomia de que se aprende nas escolas e/ou nas instituiçôes formadoras e se aplica esse saber no trabalho. Hoje, o ensinar e o aprender extrapolam o espaço das instituições formadoras. Não é necessário estar na escola para ensinar e estar no trabalho para exercitar o aprendido, se aprende e se ensina em qualquer ambiente.

Entretanto, não se rompeu ainda a autoridade de conferir a certificação. Esta continua restrita às instituiçóes autorizadas, o que ilustra uma forma de manter o controle da população, de exercer a governabilidade (FOUCAULT, 2008b).

\section{A escolarização do público da educação especial: uma teia com muitos nós}

A escolarização das pessoas que constituem o público da educação especial no Brasil é um terreno ardiloso. No entanto, não há como fugir dos desafios e controvérsias presentes nesta arena.

Um dos vieses responsáveis por esta questão é justamente o fato da "autorização", do "dar voz" a esse grupo de pessoas, que historicamente foi pensado e dimensionado pela sociedade majoritária que não vivencia a experiência de viver e/ ou produzir sua existência dentro de um contexto no qual ocorre as construçóes das pessoas que constituem o público da educação especial. Socialmente, estas são consideradas como pessoas "limitadas", no máximo com potencial para o concreto, para o fazer mecânico, reproduzindo sem habilidade para pensar, planejar, modificar e criar algo novo.

Mesmo com o reconhecimento social das diferenças, fruto do movimento de inclusão, como condição elementar à constituição de um sujeito ${ }^{3}$ pleno de potencial, ainda há um resquício generalizado da necessidade de um "autorizar-se",

3 Sujeito, neste texto, se entende como aquele com potencial para agir, para promover sua existência, fazer escolhas, atuar como cidadão, pleno em direito e deveres para com a sociedade em geral. 
para que estas pessoas exercitem todas as suas condiçốes enquanto cidadás de direito e de fato na sociedade. Há que se vencer esse vício táo presente no cotidiano que envolve a presença de profissionais da educação ou de outras áreas.

Historicamente, era reservado ao público-alvo da educação especial poucas possibilidades de experiências escolares. Estas, quando ocorriam, eram reservadas até o fim do ensino fundamental, quando muito, ao ensino médio. Não havia a possibilidade de se pensar uma pessoa com alguma deficiência ou transtorno global do desenvolvimento na Educação Superior. Neste processo histórico, esse grupo de sujeitos foi silenciado, conduzido, ignorado em suas reais condiçóes, "protegido", assimilado e nominado pelo outro fora deste contexto, em suma, violentado, obscurecido, normatizado e normalizado (SKLIAR, 2003; FOUCAULT, 2008a).

Entretanto, nas últimas décadas, esse movimento tem sofrido alteraçóes. No tocante à abrangência das possibilidades, hoje já existem pessoas desse grupo graduadas, licenciadas e pós-graduadas. A busca por cursos na modalidade tecnológica é um pouco menor, mas existe.

Apesar desses avanços, ainda há necessidade de se estabelecer uma mudança de rumo nesse processo formativo e, para tanto, é salutar considerar "o que deve mudar? Quem é o sujeito anunciado na mudança? Como deve ser produzida a mudança? Onde se realiza a mudança? Que tipo de racionalidade/s subjazem na mudança?” (SKLIAR, 2003, p.31).

Não se trata de formar um profissional com qualificação específica para uma área educaçáo especial, mas de ter no seu currículo a possibilidade de formar o profissional com conhecimentos básicos elementares para atuar nos processos de escolarização na educação básica com o público real existente nas escolas.

A sociedade está carente desses profissionais. A sua presença nas instituiçôes de educação básica modificaria as condiçóes de ensino e de aprendizagem dos estudantes de maneira geral. A longo prazo, esta situação modificaria a realidade da educação superior, dos cursos de formação de formadores e pesquisadores (mestrados e doutorados acadêmicos e profissionais).

A questão é que os nós da teia da escolarização das pessoas que constituem o público da educação especial são visíveis, mas as alternativas para seus desmanches não são assumidas como políticas públicas educacionais. Existe uma névoa que impede que se enxergue possibilidades diferentes para se olhar a mesma realidade. Estabeleceu-se uma direção e caminha-se para ela, utilizando as mesmas estratégias: a inclusão educacional radical, com a inserção de todos em salas comuns, mesmo que os incluídos não estejam se sentido felizes e produtivos nesses locus. Não existem possibilidades de escolhas.

Não há outras formas de garantir a escolarização real da população da educação especial sem cercear suas potencialidades? Isto sim representaria a sua inclusão educa- 
cional e social: significa a garantia de escolhas democráticas de formação profissional. Não é isso que faz o cidadão em geral?

Por que este movimento não deixa que surjam novas formas de entender a realidade? Por que os próprios interessados não podem pensar e falar sobre si e sobre suas expectativas pessoais e profissionais?

É preciso desnaturalizar as práticas cristalizadas, endereçadas, e deixar que os próprios interessados pensem e produzam conhecimentos envolvendo os três pilares da formação, explorados anteriormente. Que eles encontrem caminhos, estratégias pedagógicas que respondam às suas demandas e compartilhem com os demais. Para tanto, eles precisam ter a oportunidade de participar dos processos de formação nos ambientes de graduação e pós-graduação: que se tornem formadores, formadores de formadores, enfim pesquisadores. Por conseguinte, é necessário, ainda, que nesses espaços eles encontrem profissionais capazes de lhes oferecer os suportes gerais e os pedagógicos específicos para que o acesso ao conhecimento seja real.

\section{A confluência entre formação docente e a escolarização do público da educação especial: atando novos nós, pintando novas paisagens}

A formação de professores para atuar em escolas inclusivas, portanto, para escolarizar o público da educação especial, é uma realidade iniciada. A questão que se coloca é: qual formação tem sido realizada? Esta formação encontra-se compromissada com que grupo? Quais as dificuldades e as potencialidades na formação de professores, para atuar neste campo, estão desenhadas atualmente? Que tons e cores deseja-se dar às propostas de formação futuras? São muitas as perguntas, aqui são demarcadas apenas algumas delas.

Em uma rápida visita aos projetos e programas de formação docente de professores se identifica a existência de uma preocupação central, focada na aquisição de conhecimentos específicos e pedagógicos capazes de escolarizar a maioria dos estudantes, mas não preocupada com aqueles que, por diversos motivos, necessitam de caminhos diferentes para percorrer esse percurso de escolarização.

As pessoas que constituem o público da educação especial podem conseguir percorrer todos os níveis de escolarização com sucesso? Poderão escolher outros cursos que não os de licenciatura e atuar em outras áreas? O que assim os impede? As condiçôes de comunicação? As formas de registro? Os equipamentos de trabalho? $\mathrm{Ou}$ as expectativas e condiçôes de trabalho atuais não conseguem incorporá-los? Nesta última situação, a formação oferecida não estaria sendo realizada de forma táo fragilizada que os levaria a compor o "exército de reserva" necessário à manutenção do sistema capitalista?

Tais práticas evidenciam o não compromisso com o estabelecimento de condições reais de inclusão educacional e social. Ao contrário, se se pretende investir em 
condiçóes reais para a inclusão de estudantes demandantes da educação especial, todas as licenciaturas deveriam assumir a construção de um novo modelo formativo.

O curso de pedagogia forma o professor que irá atuar na educação infantil e nos primeiros anos do ensino fundamental, além do pedagogo, que irá atuar nos espaços de gestáo e de pesquisador. Para tanto, necessitaria apresentar um diferencial principal que fosse capaz de contribuir com a mudança desta realidade.

Ora, se os egressos dos cursos de pedagogia são, em regra, os responsáveis pelo processo de alfabetização dos estudantes em geral, como poderá um professor, que não recebeu uma formação ampliada, inclusive bilíngue, se tornar capaz de alfabetizar um estudante surdo? Logo, em uma educação cujo paradigma oficial tem como princípio a inclusão educacional, não teria esta que formar seus profissionais alinhados com o mesmo? Como isso é possível de ser concebido?

Isto ocorre na visão das políticas educacionais brasileiras, que não atuam preocupadas com esta realidade, transferindo para o professor e demais profissionais da educação a responsabilidade de assumir essa demanda na formação continuada e para o estudante da educação especial, o peso das dificuldades encontradas no processo de escolarizaçáo e, em muitos casos, do fracasso ocorrido.

Como um mecanismo para mascarar esta realidade, instaura-se o ensino da Libras nos cursos de licenciatura sem a definição de uma carga horária mínima, o que, consequentemente, fez com que as instituiçóes formadoras fossem obrigadas a equiparar a Libras ao braile. Não que o ensino do braile seja menos importante, mas a Libras trata-se de uma língua e o braile de um código de transcrição utilizado para a mesma língua.

Esta realidade oferece claros indícios para se encontrar uma provável resposta à pergunta que se apresenta, qual seja: com quem está compromissada esta formação? Com a comunidade composta pelo público da educação especial, com certeza, não é, mas, sim, com a política econômica que visa economizar, promover uma formação aligeirada e superficial, que permita aos formandos apenas executar e nunca problematizar.

O desafio está posto, as dificuldades ocorrerão, independentemente de esses profissionais terem ou não uma deficiência. Cabe aos envolvidos terem abertura para pensá-las e buscar alternativas para superá-las.

Por outro lado, as dificuldades na formação de professores precisam ser pensadas e assumidas pelos pesquisadores da área, envolvendo-os nesse processo, independentemente de suas condiçôes de inserção social e profissional.

Uma delas, quiçá a maior, está relacionada com a mudança de mentalidade dos profissionais envolvidos nos cursos de graduação e pós-graduação, que possuem uma visão limitada, em muitos casos preconceituosa, quanto às potencialidades e necessidades específicas relacionadas ao público da educação especial. 
Neste caso, há que se investir na acessibilidade conceitual, atitudinal e pedagógica. Em modalidades de acessibilidade mais difíceis de se instalar, por demandar mudança de conceitos e de perspectivas para interferir nos sentidos e compreensōes de mundos estabelecidos. A interferência nessas modalidades de acessibilidades demanda compromisso político com a diferença.

Outra questão a ser enfrentada, está na forma com que o próprio sujeito da educação especial tem de se envolver com esse movimento, chamando para si a responsabilidade de criar condiçóes para que a mudança ocorra. Para isso, precisa compreender o movimento no qual encontra-se imerso, pois é mais fácil se formar para ser professor de uma área específica do que assumir a responsabilidade de ser professor de qualquer componente curricular, inserindo-se nas diferentes licenciaturas, demarcando seu espaço, apresentando suas demandas, provocando rachaduras nas condiçóes preestabelecidas, para, nessas aberturas, propor novos projetos e olhares sobre a formação docente.

Há que se romper com o estigma da autorização. Não há que se esperar que a pessoa que não vive a experiência de ter uma deficiência lhe autorize a pensar e a criar espaços de atuação profissional. O sujeito precisa desejar e potencializar sua aspiração. Neste processo, existiráo dificuldades, como existem para todos, independentemente da condição de ter ou não uma deficiência.

A formação de professores, neste aspecto, depende da presença de profissionais qualificados nas instituiçóes formadoras, com conhecimentos relacionados às áreas que envolvem o público da educação especial, capazes de, nos cursos de formação inicial e continuada de professores, instrumentalizá-los para compreender a realidade e interferir na mesma de forma crítica, criativa e propositiva. É preciso abrir-lhes os horizontes.

Isto pois é preciso considerar que mudanças profundas e estruturais demandam conhecimento, elemento central que a comunidade composta pelo público da educação especial foi alijada durante muitos anos. Logo, tais construçóes não poderão surgir espontaneamente, mas há que se construir as condiçôes materiais e intelectuais para que as mesmas ocorram: uma destas condiçóes seria a transformação real de todas as licenciaturas. Seria esta proposta uma utopia?

Entretanto, uma utopia, quando coletiva e construída de forma planejada, poderá ser convertida em realidade. Estes seriam os tons e as cores que se pretende dar à formação de professores para atuar em ambientes inclusivos: uma formação que o habilite a ser professor da área que lhe for desejada, não uma formação conduzida para uma área específica, como se seu potencial fosse reduzido ao ensino de um conhecimento delimitado para os demais.

Um sonho sonhado só é apenas um sonho. Um sonho sonhado junto é realidade.

(Raul Seixas) 


\section{Referências}

BRASIL. Resolução CNE/CP 1, de 18 de fevereiro de 2002. Que institui as Diretrizes Curriculares Nacionais para a Formação de Professores da Educação Básica, em nível superior, curso de licenciatura, de graduação plena. Disponível em: http://portal.mec.gov.br/cne/arquivos/pdf/ rcp01_02.pdf. Acesso em: 5 nov. 2013.

BRASIL. Ministério da Educação. Universidade Federal de Uberlândia. Resolução n. 16/2013, do Conselho Universitário que aprova a criação do Curso de Graduaçáo em Letras, habilitação em Língua Portuguesa com domínio de Libras, Grau Licenciatura, na Universidade Federal de Uberlândia, e dá outras providências. Disponível em: http://www.reitoria. ufu.br/Resolucoes/resolucaoCONSUN-2013-16.pdf. Acesso em: 5 nov. 2013.

CASTELLS, M. A Era da Informação: economia, sociedade e cultura, v.1. Lisboa: Fundação Calouste Gulbenkian, 2002.

CASTELLS, M. A galáxia da internet: reflexóes sobre a internet, os negócios e a sociedade. Rio de Janeiro: Jorge Zahar, 2003.

COUTINHO, C.; LISBÔA, E. Sociedade da informação, do conhecimento e da aprendizagem: desafios para educação no século XXI. Revista de Educação, v.18, n.1, p.5-22, 2011.

FOUCAULT, M. Aula de 25 de janeiro de 1978: Características dos dispositivos de segurança - a normalização. In: FOUCAULT, M. Segurança, território, população. Sáo Paulo: Martins Fontes, 2008a. p.73-116.

FOUCAULT, M. Nascimento da biopolítica. São Paulo: Martins Fontes, 2008b.

HARGREAVES, A. O ensino na sociedade do conhecimento: a educação na era da insegurança. Porto: Porto Editora, 2003. (Coleção Currículo, Políticas e Práticas).

JONASSEN, D. H. Computadores, ferramentas cognitivas: desenvolver o pensamento crítico nas escolas. Porto: Porto Editora, 2007.

PELLICER, E. G. La Mod a tecnológica en la educación: peligros de un espejismo. Píxel Bit. Revista de Medios y Educación, n.9, p. 81-92, jun. 1997.

PIMENTA, S. G. Formação de professores - saberes da docência e identidade do professor. Revista da Faculdade de Educação, Sáo Paulo, v.22. n.2, p.72-89, jul.-dez. 1996.

POSTMAN, N. Tecnopolia - quando a cultura se rende à tecnologia. Lisboa: Difusão Cultural, 1992.

SKLIAR, C. Pedagogia (improvável) da diferença. E se o outro não estivesse aí? Rio de Janeiro: DP\&A, 2003. 


\section{Resumo}

\section{Formação de professores: desafios à educação inclusiva}

Este texto tem o compromisso de trazer algumas reflexóes situando o universo da formação docente e o universo da escolarização do público da educação especial. Buscar-se-á correlacionar essas duas áreas que a princípio parecem distantes, mas que, para entender as características e compromissos da qualificação para o exercício da docência, precisam ser articuladas. Este texto irá trabalhar a formação docente de maneira geral, depois as características imanentes do público da educação especial ${ }^{4}$ e, no terceiro momento, a confluência entre ambos. A formação de professores para atuar em escolas inclusivas, para escolarizar o público da educação especial é uma realidade iniciada. A questão que se coloca é: qual formação tem sido realizada? Esta formaçáo encontra-se compromissada com que grupo? Quais dificuldades e potencialidades para a formação de professores para atuar neste campo estão desenhadas atualmente? Que tons e cores deseja-se dar às propostas de formação futuras? São muitas as perguntas, aqui são demarcadas apenas algumas delas. Reflexôes sobre essas questóes envolvem este artigo. Há que se investir na acessibilidade conceitual, atitudinal e pedagógica. A interferência nestas modalidades de acessibilidade demanda compromisso político com a diferença.

Palavras-chaves: Formação Docente. Inclusão Educacional. Acessibilidade.

\section{Abstract}

\section{Training Teachers: Challenges to Inclusive Education}

This text is committed to start this process by bringing some reflections situating the universe of teacher education and the world of public schooling for persons of special education. It will seek to correlate these two areas that initially seem distant, but to understand the characteristics and commitments of qualification for the exercise of teaching need to be articulated. This text will work with teacher education in general, then, the inherent characteristics of public special education and in the third moment the confluence of both. Training teachers to work in inclusive schools to educate the public of special education is an initiated reality. The question that arises is: What training has been accomplished? This formation lies committed to that group? What difficulties and potentialities for the training of teachers to work in this field are currently designed? What tones and colors are hoped to give to the proposals for future training? There are many questions; these are just some of them. Reflections on these issues involve this article. One must invest in conceptual, attitudinal and pedagogical accessibility. The interference of these modes of accessibility demand political commitment with the difference.

Keywords: Teacher Training. Educational Inclusion. Accessibility.

4 Desde 2008, o público da educação especial no Brasil são as pessoas com deficiência (física, sensorial e mental), com transtornos globais do desenvolvimento e com altas habilidades/superdotação. 